\title{
Comparison of centralized, semi-centralized and decentralized sanitation systems
}

\author{
I. Obermann \& K. Sattler \\ Gesellschaft fuer Internationale Zusammenarbeit (GIZ) GmbH, Germany
}

\begin{abstract}
This study assists in identifying suitable and sustainable sanitation systems under specific local conditions.

In order to fulfil this objective, two different assessments were conducted.

Six selected decentralized, semi-centralized and centralized sanitation systems were assessed against five sustainability key groups and their subcriteria.

Afterwards, the suitability of the sanitation systems under six defined local scenarios was evaluated. An overview about advantages and disadvantages of the six sewage systems and their field of application was given.

The developed system was exemplarily applied to the city of Shillong (India) resulting in the step by step implementation of different measures.

Since the implementation of a large central sewage system requires long time periods, dividing the implementation process into various phases with interim stages is suitable in order to take early action on increasing the quality of surface waters and public health. This is done to mitigate health risks for the population while mid- and long-term measures are performed. The combination of different measures is inevitable.

Keywords: decentralized, semi-centralized, centralized sanitation, constructed wetlands, household septic tank, waste water treatment plant, assessment.
\end{abstract}

\section{Introduction}

Sustainable sanitation is crucial in preventing disease, environmental destruction and economic stagnation. Selecting the right sanitation system in any given circumstance requires thorough assessment of both the characteristics of a 
system as well as the local conditions. This study is an attempt to do both and thus assist in the selection of sustainable sanitation systems.

\section{Objective}

The key objective of the study is to assist in identifying suitable and sustainable sanitation systems under specific local conditions. In order to fulfil this objective, two different assessments were conducted in this study:

- Assessment of different decentralized, semi-centralized and centralized sanitation systems against 5 sustainability key groups.

- Evaluation of the suitability of six selected sanitation systems under 6 defined local scenarios.

\section{Methodology}

The identification of sustainability criteria, sanitation systems and local scenarios, the definition of their realistic characteristics as well as the assessment of sanitation systems against sustainability criteria and their evaluation under different local scenarios was based on literature review, practical experience by the authors and interviews with other sector experts. Assessments were done by applying a numeric system including the numbers $0,1,2$, with 0 standing for 'weak', 1 for 'medium' and 2 for 'good' compliance. In the assessment against sustainability criteria, scoring was done for each parameter under the five sustainability key groups. Average results for each of the five sustainability groups were then calculated.

\section{Identification of sustainability criteria}

Five sustainability key groups were first identified against which the sanitation systems were later assessed:

1. Health and hygiene

- Users risks

- Operational staff risks (+emptier)

- Treatment efficiency of pathogenic germs

2. Environment and natural resources

- Risk of groundwater contamination

- Water requirements

- Energy requirements

- Other resources(construction)

- Reuse fertilizer, water

- Treatment efficiency C, N, P

3. Technology and operation

- System robustness (service life)

- Vulnerability

- System flexibility (adaptability) 
- Ease of construction (local materials)

- Requirements for HR (quantity)

- Simplicity of operation

- Maintenance requirements

- Requirement for sewer

4. Financial and economic issues

- Capital costs

- O\&M costs

5. Socio-cultural and institutional aspects

- Regulation and control function

- Convenience

- Smell

- Privacy, security

\section{Identification of sanitation systems and definition of their characteristics}

For this study six common sanitation systems were identified and their basic characteristics defined. It shall be mentioned that the selection and definition of scenarios shall not represent all existing different sanitation systems, but are common ones in many areas. To be able to cover a wide range of scenarios, two systems were selected from each of the categories decentralized systems, semicentralized systems and centralized systems. So at first, these three categories had to be defined, which was done by the population equivalent (PE) connected to a certain system. Second, two common sanitation systems were selected for each category (total of six), and finally their key characteristics defined.

Decentralized sanitation systems were defined to be limited to single or several households with a maximum capacity of up to 20 persons. The two decentralized sanitation systems selected were household pit latrine and household septic tank. It was assumed that pit latrines can be constructed and maintained by the users and are operated as a dry or pour flush system. Septic tanks usually work with pour flush or flush. They are designed to be emptied periodically and transported to treatment plants by suction trucks.

Semi-centralized systems are defined in various ways in the literature. They generally can be categorized by their number of connections of households, or by the outline of the sewer system relative to the central sewerage system. For the first option, the numbers of connected households to semi-centralized systems vary greatly in the literature, ranging from several dozens to several tens of thousands. For this study, semi-centralized systems were defined to have enough treatment capacity for small villages, communities or districts of about 1,000 10,000 people. It was also defined that the semi-centralized sanitation systems analyzed in this study (small wastewater treatment plants and constructed wetlands) would be connected to sewer systems.

Centralized systems generally have a wide range and high number of people connected, which in this study is defined as more than PE $>50,000$. Sewerage 
and flush systems are required, as well as high capacities for construction and maintenance. The selected sanitation systems as well as their key characteristics are summarized in table 1.

Table 1: $\quad$ Selected sanitation systems and their general characteristics.

\begin{tabular}{|l|c|c|c|c|c|c|}
\hline Characteristics & \multicolumn{2}{|c|}{$\begin{array}{c}\text { Decentralized } \\
\text { systems }\end{array}$} & \multicolumn{2}{c|}{$\begin{array}{c}\text { Semi-centralized } \\
\text { systems }\end{array}$} & \multicolumn{2}{c|}{$\begin{array}{c}\text { Centralized } \\
\text { systems }\end{array}$} \\
\hline & $\begin{array}{c}\text { Household } \\
\text { pit latrine }\end{array}$ & $\begin{array}{c}\text { Household } \\
\text { septic tank }\end{array}$ & $\begin{array}{c}\text { Small } \\
\text { WWTP } \\
\text { activated } \\
\text { sludge) }\end{array}$ & $\begin{array}{c}\text { Constructed } \\
\text { wetland }\end{array}$ & $\begin{array}{c}\text { Biofilm: } \\
\text { trickling } \\
\text { filter }\end{array}$ & $\begin{array}{c}\text { Activated } \\
\text { sludge }\end{array}$ \\
\hline PE connected & \multicolumn{2}{|c|}{$<20$} & \multicolumn{2}{c|}{1,000 to 10,000} & \multicolumn{2}{c|}{$>50,000$} \\
\hline Construction by users & $\mathrm{x}$ & $\mathrm{x}$ & & & & \\
\hline Maintenance by users & $\mathrm{x}$ & & & & & \\
\hline Dry flush & $\mathrm{x}$ & & & & & \\
\hline Pour flush & $\mathrm{x}$ & $\mathrm{x}$ & & & & $\mathrm{x}$ \\
\hline Flush & & $\mathrm{x}$ & $\mathrm{x}$ & $\mathrm{x}$ & $\mathrm{x}$ & $\mathrm{x}$ \\
\hline Sewerage network & & & $\mathrm{x}$ & $\mathrm{x}$ & $\mathrm{x}$ & $\mathrm{x}$ \\
\hline Treatment at WWTP & & $\mathrm{x}$ & $\mathrm{x}$ & $\mathrm{x}$ & $\mathrm{x}$ & $\mathrm{x}$ \\
\hline
\end{tabular}

\section{Identification and of local scenarios and definition of their characteristics}

Six local scenarios were defined under which all six sanitation systems were then to be evaluated. The selection of scenarios and definition of their general characteristics was done based on representation of typical and wide-spread circumstances. The three chosen parameters to describe the scenarios were type of water supply (fetched or piped), existence of sewerage system (yes or no) and vehicular access (easy or difficult). Table 2 summarizes the six selected local scenarios as well as their underlying characteristics defined in this study.

Table 2: $\quad$ Definition of local scenarios and key characteristics.

\begin{tabular}{|c|l|c|c|c|}
\hline & Scenario & \multicolumn{3}{|c|}{ Characteristics } \\
\hline & & $\begin{array}{c}\text { Water } \\
\text { supply }\end{array}$ & $\begin{array}{c}\text { Sewerage } \\
\text { system }\end{array}$ & $\begin{array}{c}\text { Vehicular } \\
\text { access }\end{array}$ \\
\hline 1 & Rural area I $\left(<100\right.$ people $\left./ \mathrm{km}^{2}\right)$ & Fetched & No & Difficult \\
\hline 2 & Rural area II $\left(<100\right.$ people $\left./ \mathrm{km}^{2}\right)$ & Piped & No & Difficult \\
\hline 3 & Town $\left(1,000-10,000\right.$ people $\left./ \mathrm{km}^{2}\right)$ & Piped & No & Easy \\
\hline 4 & City $\left(>10,000\right.$ people $\left./ \mathrm{km}^{2}\right)$ & Piped & Yes & Easy \\
\hline 5 & Slum & $\begin{array}{c}\text { public water } \\
\text { points }\end{array}$ & No & Difficult \\
\hline 6 & New settlement & Piped & Yes & Easy \\
\hline
\end{tabular}




\section{Results of assessments}

The six sanitation systems were first examined against the selected sustainability criteria, and then before the background of these results evaluated on their suitability under each scenario. The evaluation thus resulted in the identification of appropriate sanitation systems or combinations of them for each scenario (see table 3).

Table 3: Assessment of sanitation systems against key sustainability criteria.

\begin{tabular}{|l|c|c|c|c|c|c|}
\hline & \multicolumn{2}{|c|}{ Decentralized systems } & \multicolumn{2}{|c|}{$\begin{array}{c}\text { Semi-centralized } \\
\text { systems }\end{array}$} & \multicolumn{2}{|c|}{$\begin{array}{c}\text { Centralized } \\
\text { systems }\end{array}$} \\
\hline $\begin{array}{l}\text { Criteria for } \\
\text { sustainable } \\
\text { sanitation }\end{array}$ & $\begin{array}{c}\text { Household pit } \\
\text { latrine }\end{array}$ & $\begin{array}{c}\text { Household } \\
\text { septic tank }\end{array}$ & $\begin{array}{c}\text { Small WWTT } \\
\text { (activated } \\
\text { sludge }\end{array}$ & $\begin{array}{c}\text { Constructed } \\
\text { wetland }\end{array}$ & $\begin{array}{c}\text { WwTP: } \\
\text { trickling filter }\end{array}$ & $\begin{array}{c}\text { WWTP: } \\
\text { activated } \\
\text { sludge }\end{array}$ \\
\hline Health and hygiene & 0.3 & 1.0 & 1.7 & 1.3 & 1.7 & 1.7 \\
\hline $\begin{array}{l}\text { Environment and } \\
\text { natural resources }\end{array}$ & 1.0 & 1.0 & 1.0 & 1.0 & 1.0 & 0.8 \\
\hline $\begin{array}{l}\text { Technology and } \\
\text { operation }\end{array}$ & 1.5 & 1.8 & 0.4 & 0.9 & 0.4 & 0.0 \\
\hline $\begin{array}{l}\text { Financial and } \\
\text { economic issues }\end{array}$ & 2.0 & 1.5 & 0.5 & 1.0 & 0.5 & 0.0 \\
\hline $\begin{array}{l}\text { Socio-cultural and } \\
\text { institutional aspects }\end{array}$ & 0.8 & 1.5 & 1.3 & 1.5 & 1.8 & 1.8 \\
\hline \hline \hline Mean values & 1.1 & 1.4 & 1.0 & 1.2 & 1.1 & 0.9 \\
\hline
\end{tabular}

Rating: 0 for 'weak' (0-0.5), 'medium' (0.6-1.4) and for 'good' (1.5-2).

Regarding sustainability criteria, the household septic tank had the overall best score. Under realistic and not ideal assumptions, the household septic tank has disadvantages in health and hygiene (only household pit latrine was given a lower score in that category), but scores high in most other categories. The three systems small WWTP, biofilm: trickling filter, and WWTP (activated sludge) all have big disadvantages in the categories 'financial and economic issues' as well as 'technology and operation', as all three systems require high capacities, which are often unavailable. Somewhere in the middle the technology 'constructed wetland' can be placed, which has high or average scores in all five categories.

Keeping the results of the sustainability assessment in mind, the six sanitation systems were then evaluated under the six scenarios described above (see table 4).

Household septic tanks got the overall highest score, with their biggest asset being their flexibility and thus applicability in very different scenarios. There is no scenario under which they were classified as not appropriate (' 0 '), they scored 
Table 4: $\quad$ Assessment of sanitation systems against local scenarios.

\begin{tabular}{|c|c|c|c|c|c|c|}
\hline & \multicolumn{2}{|c|}{$\begin{array}{l}\text { Decentralized } \\
\text { systems }\end{array}$} & \multicolumn{2}{|c|}{$\begin{array}{l}\text { Semi-Centralized } \\
\text { systems }\end{array}$} & \multicolumn{2}{|c|}{$\begin{array}{l}\text { Centralized } \\
\text { systems }\end{array}$} \\
\hline Scenario & $\begin{array}{c}\text { Household } \\
\text { pit latrine }\end{array}$ & $\begin{array}{l}\text { Household } \\
\text { septic tank }\end{array}$ & $\begin{array}{c}\text { Small } \\
\text { WWTP } \\
\text { (activated } \\
\text { sludge) }\end{array}$ & $\begin{array}{l}\text { Constructed } \\
\text { wetland }\end{array}$ & $\begin{array}{l}\text { WWTP: } \\
\text { trickling } \\
\text { filter }\end{array}$ & $\begin{array}{l}\text { WWTP: } \\
\text { activated } \\
\text { sludge }\end{array}$ \\
\hline $\begin{array}{l}\text { Rural area I } \\
\text { (fetched water } \\
\text { supply) }\end{array}$ & 2 & 2 & 0 & 0 & 0 & 0 \\
\hline $\begin{array}{l}\text { Rural area II } \\
\text { (piped water } \\
\text { supply) }\end{array}$ & 1 & 1 & 0 & 2 & 0 & 0 \\
\hline $\begin{array}{l}\text { Town } \\
<10,000 \\
\text { people } / \mathrm{km}^{2} \\
\end{array}$ & 1 & 2 & 2 & 2 & 0 & 0 \\
\hline $\begin{array}{l}\text { City } \\
10,000 \\
\text { people } / \mathrm{km}^{2}\end{array}$ & 0 & 1 & 1 & 1 & 2 & 1 \\
\hline$\underline{\text { Slums }}$ & 1 & 1 & 0 & 0 & 0 & 0 \\
\hline New settlement & 0 & 1 & 2 & 2 & 2 & 1 \\
\hline
\end{tabular}

Rating: 0 standing for 'weak', 1 for 'medium' and 2 for 'good'.

average (' 1 ') in four scenarios and most appropriate (' 2 ') in rural areas with fetched water supply and small towns with wastewater network. Their flexibility is to a large extent due to the fact that they can be operated in systems with and without sewers (as long as vehicular access is feasible), and in the second option can be relatively easy upgraded to becoming connected to sewerage networks at a later stage. This makes them very suitable as a mid-term solution in many scenarios. In slums, due to lack of space, vehicular access and financial and operational capacities, they are together with pit latrines the only suitable technologies. Other solutions have to go together with wider city planning and development.

Both household pit latrines and constructed wetlands are also quite flexible technologies, though being suitable in different scenarios. Pit latrines scored high ('2') obviously in rural areas without wastewater networks and average in rural areas with piped water supply, small towns, slums. Their main disadvantage when being connected to a flush system is their small tanks and thus low capacities, their advantage in densely populated and poor areas their low need in space and having at least some treatment capacity without being connected to sewerage system.

Constructed wetlands are cheap, easy to operate and have a relatively high treatment capacity, with their main requirement being space. This makes them highly suitable (scoring ' 2 ') in rural areas (particularly with sewerage network), small towns and new settlements. 
The other three analyzed systems - small WWTP, biofilm: trickling filter and activated sludge - got high scores under specific scenarios but have little flexibility. Small WWTP are most suitable in towns and new settlements, for which they have enough treatment capacity and are cheaper and easier in operations and maintenance than large treatment plants. In bigger cities, it can be assessed whether several small WWTPs, which are installed step by step following the population rise, are more efficient than large WWTP. Large WWTP using biofilm or activate sludge technologies are only efficient under high operators' capacities and with high connection numbers, which they can only achieve in cities and potentially large new settlements.

\section{Example: Shillong, Meghalaya, Northeast India}

Shillong, the capital city of the state Meghalaya, is located in North-East India. The city covers an area of approx. $10 \mathrm{~km}^{2}$ and is inhabited by 140,000 people, leading to a high density of ca. 14,000 people per square kilometer. In the last decades the city experienced a strong increase in inhabitants.

Two rivers run through Shillong from East to West. WahUmkrah further north and Umshyrpi in the south of city. After they unite west of Shillong they enter Umiam River which flows into Umiam Lake (see figure 1).

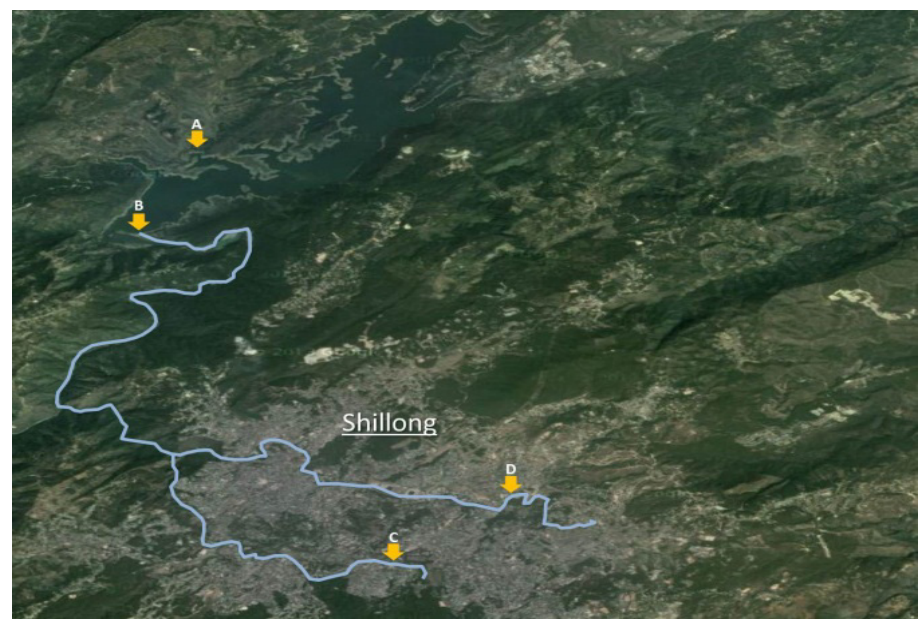

Figure 1: $\quad$ Map of Shillong with exemplary monitoring locations.

The Umiam Lake is used as source for drinking water supply after treatment. Furthermore, the surface waters of Meghalaya are used for irrigation, bathing and washing (see figure 2). In Shillong, no central sewerage or sewage system exists. Household grey water (water from kitchen, washing, bathing) is discharging via open channels directly into the natural environment. Private toilets are connected with private septic tanks and these tanks are planned to be emptied and the sludge evacuated regularly with suction trucks. Analyses of 


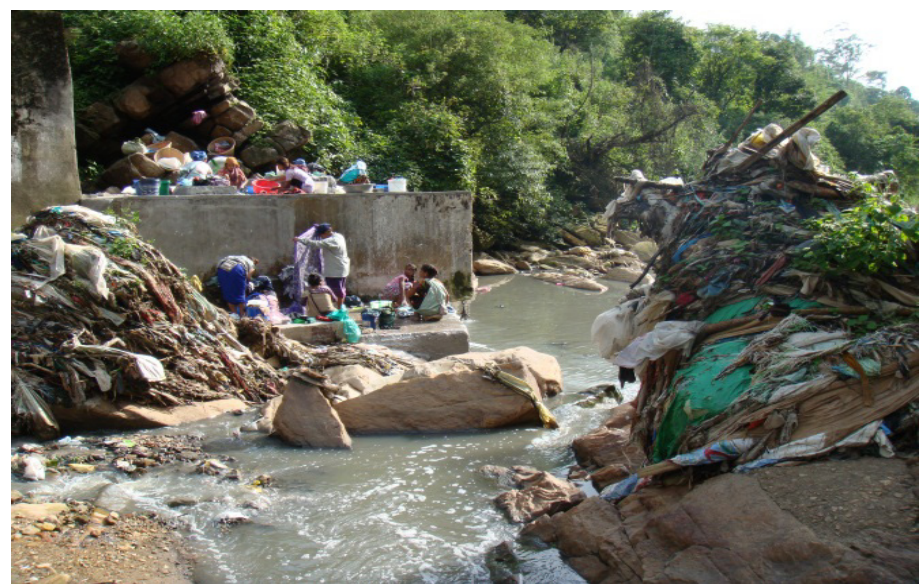

Figure 2: $\quad$ Location at Umshyrpi river for washing.

Meghalayan surface waters in January 2012 (according to Meghalaya State Pollution Control Board) revealed extreme values for several of the 47 surface water monitoring locations. Measured data for four locations are exemplary shown in table 5. High electrical conductivities indicate pollutions through industrial discharge. Total coliform and BOD concentrations indicates household water intake and the concentrations at the rivers Umkhrah and Umshyrpi. Dissolved oxygen concentrations at five monitoring stations at these rivers are below $4 \mathrm{mg} / \mathrm{l}$. Action needs to be taken to increase the quality and identify the sources of pollution of surface waters in Meghalaya in order to mitigate health risks for the population.

The presented scheme was applied exemplary for Shillong in order to draft first recommendations for adequate sanitation systems for short-, mid- and longterm adapted measures.

Table 5: $\quad$ Examples of analyses of Meghalayan surface waters (01/2012; source: Meghalaya State Pollution Control Board, locations A-D as shown in Figure 1).

\begin{tabular}{|l|c|c|c|c|}
\hline Parameter & $\begin{array}{c}\text { Location } \\
\text { A }\end{array}$ & $\begin{array}{c}\text { Location } \\
\text { B }\end{array}$ & $\begin{array}{c}\text { Location } \\
\text { C }\end{array}$ & $\begin{array}{c}\text { Location } \\
\text { D }\end{array}$ \\
\hline Conductivity $[\mu \mathrm{S} / \mathrm{cm}]$ & 100 & 150 & 270 & 180 \\
\hline Dissolved Oxygen $[\mathrm{mg} / \mathrm{L}]$ & 7 & 6 & 1 & 6 \\
\hline BOD $[\mathrm{mg} / \mathrm{L}]$ & 8 & 10 & 95 & 20 \\
\hline COD [mg/L] & 18 & 20 & 150 & 35 \\
\hline Total Coliform $[\mathrm{MPN} / 100 \mathrm{ml}]$ & $4 \times 10^{2}$ & $6 \times 10^{2}$ & $1 \times 10^{5}$ & $2 \times 10^{4}$ \\
\hline Total dissolved solid $[\mathrm{mg} / \mathrm{L}]$ & 85 & 125 & 230 & 155 \\
\hline
\end{tabular}

Shillong with a density of approx. 14,000 people per square kilometer exceeds in this context according to the definition of table 4 slightly the size of scenario “Town” $\left(<10,000 \mathrm{p} / \mathrm{km}^{2}\right)$. 
In order to identify appropriate sanitation systems for Shillong, the sanitation systems with the best results ( 2 = 'good') for both scenarios "City" and "Town" were applied. Those are Septic tanks, small wastewater treatment plant (activated sludge), constructed wetlands and wastewater treatment plants with trickling filter (see table 4).

Shillong is a densely built-up area with difficult topography. Therefore constructed Wetlands, which have a high demand for space, are no suitable solution.

Building up a central sewerage and sewage system is a long-term project. In the meantime short-term and mid-term solutions with semi-central extent have to be implemented.

In Shillong the following implementation strategy is recommended:

1. Short-term: 2 years Improvement of septage management (household septic tank)

2. Mid-term: 5 years

Implementation of semi-central small wastewater treatment plants (activated sludge) for approx. $100 \mathrm{~m}^{3} / \mathrm{d}$ each at identified hot spots, wastewater collection from existing open channels

3. Long-term: 10 years

Extension of sewerage network and implementation of up to three central wastewater treatment plants (e.g. trickling filter).

The main challenge in a city like Shillong without existing sewerage network and wastewater treatment is to implement immediate measures on hotspots to increase the quality of surface waters in order to mitigate health risks for the population. These immediate measures have to be independent from timeconsuming sewerage construction with extent traffic-disturbing effects.

Mid- and long-term measures incorporate the steadily construction of wastewater sewers (including pumping stations). The solution is not one measure but the right combination and timing of different measures adapted to local situations.

\section{References}

[1] Deutsche Vereinigung fuer Wasserwirtschaft, Abwasser und Abfall e.V. (2008): Bewertung von Verfahrensstufen zur Abwasseraufbereitung fuer die Wiederverwendung, Hennef, 2008.

[2] Sustainable Sanitation Alliance: Towards More Sustainable Sanitation Solutions, 2008

[3] Sustainable Sanitation and Water Management Toolbox, www.sswm.info

[4] Tilley, E. et al. Compendium of Sanitation Systems and Technologies. Swiss Federal Institute of Aquatic Science and Technology (Eawag): Duebendorf, (Switzerland), 2008. 